\title{
Role of labour in the establishment of functional residual capacity at birth
}

\author{
H VYAS, A D MILNER, I E HOPKIN, AND A D FALCONER \\ Department of Neonatal Medicine and Surgery, The City Hospital, and Department of Physiology, Queens \\ Medical Centre, Nottingham
}

SUMMARY Intrathoracic pressure and volume changes were measured during the spontaneous first breath in 11 healthy term neonates delivered by emergency caesarean section (CS). Although inspiratory and expiratory rates were higher than those found among babies delivered by elective CS, inspiratory volume was very similar and these babies, unlike those delivered by elective CS, had all formed a functional residual capacity at the end of the first breath. We obtained cord arterial and venous samples for catecholamine analysis concurrently, and found that most of the babies had concentrations of plasma noradrenaline similar to babies delivered by elective CS-high values were found only among infants who had suffered fetal distress. Both catecholamine excretion and method of delivery may be important in the formation of the functional residual capacity at birth.

Soon after birth when spontaneous respiration begins the fetal lung takes on a vital function. There is strong evidence, however, that preparation for lung expansion is initiated by the onset of labour. In 1963, Segal and $\mathrm{Chu}^{1}$ observed a statistically significant difference between babies delivered by elective caesarean section (CS) and those delivered vaginally. The former group had a consistently lower crying vital capacity. Two further studies ${ }^{2} 3$ have been able to confirm this, and Milner et al. ${ }^{4}$ showed marked differences in the thoracic gas volume in the first 6 hours of life, finding that babies delivered by elective CS had a strikingly lower thoracic gas volume (mean $19.7 \mathrm{ml} / \mathrm{kg}$ ) than babies delivered vaginally (mean $32.7 \mathrm{ml} / \mathrm{kg}$ ). Boon et al. ${ }^{5}$ studied thoracic gas volumes in 25 babies delivered vaginally, 15 delivered by elective CS, and 7 by emergency CS and found that thoracic gas volumes were highest in the first group, lowest in the second group, and that babies delivered by emergency CS formed an intermediate group. These differences were not important by 48 hours.

In our previous study ${ }^{6}$ of intrathoracic pressure and volume changes during spontaneous first breaths in babies delivered vaginally and by elective CS similar inspiratory pressures and volumes were found, but the initial functional residual capacity (FRC) - the air remaining in the lungs at the end of the first breath-was formed less frequently in elective CS babies. 'Vaginal squeeze' during delivery that was not experienced by the elective CS babies may have caused this difference.

Animal studies 7 show that the process of labour reduces lung water content independent of the mode of delivery. Walters and Olver ${ }^{8}$ have elucidated the role of catecholamines in lung fluid absorption in sheep and recently Brown et al. ${ }^{9}$ showed (again in sheep) the progressive slowing down of lung liquid secretion followed by absorption during labour, and correlated this with increasing adrenaline concentrations. There have been reports of high plasma catecholamine concentrations in human neonates after vaginal delivery ${ }^{10-13}$ and catecholamines may therefore play a similar role in humans.

We studied the pressure and volume changes during the spontaneous first breath in 11 babies delivered by emergency CS-that is after onset of labour-to determine the role of labour in the formation of the FRC, and compared these results with those of our previous study. ${ }^{6}$ In addition we obtained umbilical arterial and venous samples from 16 babies delivered by emergency CS, for measurement of plasma catecholamine concentrations. Seven of the 16 samples were taken from the 11 babies in whom lung function was studied.

\section{Patients}

The gestational age of all infants was confirmed by the maternal menstrual history. All were born at 
Table 1 Clinical details

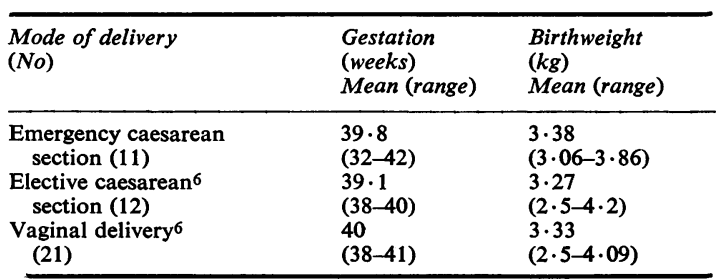

37 weeks' gestation or more except for 1 baby who was delivered at 32 weeks'. One mother had essential hypertension that was treated with methyldopa ( $250 \mathrm{mg}, 4$ times a day), but none of the other 15 mothers had a history of renal, hypertensive, or metabolic disease. All the babies had Apgar scores of 5 or over at 2 minutes and none needed any active resuscitation. The mothers of the 11 babies in whom lung function was studied had been in labour for a mean of 11.5 hours and the indications for delivery by emergency CS were failure to progress (7), fetal distress (2), suspected rupture of the uterus (1), and a planned elective CS mother who had gone into spontaneous labour (1). Five deliveries were performed under epidural anaesthesia and 6 under general anaesthesia. All parents gave their consent before the investigation and the study was approved by the health district ethical committee.

\section{Methods}

Lung function measurements. Intrathoracic pressure was measured using a Gaeltec catheter tip pressure transducer. The catheter was formed by covering a nylon tube containing the electrical conductors with a flexible steel braid. A single piece of metal alloy formed the sensor. The size of the catheter was 6 FG. Flow signals were recorded by mounting a Fleisch pneumotachograph in the orifice of an anaesthetic mask that was modified by substituting the pneumatic flange with a soft foam rim, coated with latex to make it airtight. Signals from the pneumotachograph were conducted to the differential pressure transducer (ES EM 3k).

Signals from the oesophageal transducer and the differential pressure transducer were amplified by EMMA amplifier and recorded on a 4 channel tape recorder (Racal). The transducers and the amplifier were fitted to a modified Resuscitaire (Vickers). Visual display was obtained on a 4 channel oscilloscope. At the end of the recording calibration was carried out. Flow was calibrated using a rotometer, volume with a $50 \mathrm{ml}$ syringe, and the Gaeltec transducer by submerging it to a known depth of water. The rise time of the transducer was $10 \mu \mathrm{s}$, giving a $3 \mathrm{db}$ attenuation at $15 \mathrm{~Hz}$ and the corresponding values for the pneumotachograph were $6 \mu \mathrm{s}$ and $5.7 \mathrm{~Hz}$ respectively. The signals were fed through a 6 channel oscillograph for analysis and the results were obtained on ultraviolet sensitive paper. During this procedure flow signals were also channelled through an electronic integrator and volume was thus obtained.

The pressure transducer and the pneumotachograph were sterilised by immersing them in 5\% chlorhexidine in $70 \%$ alcohol for 5 minutes, and plastic tubings used for transmitting flow signals to the transducer were autoclaved. After delivery of the baby's head through the uterine incision, the pressure transducer was passed transnasally to a premeasured amount $(16 \mathrm{~cm})$ that we know from previous experience places it in the lower third of the oesophagus. The face mask was then lowered over the baby's face, enclosing the nose and mouth. The latex coating on the mask together with the fluid surrounding the face formed an airtight seal. The procedure took only 30 seconds, after which the baby was delivered normally and placed on its side. Recording began before delivery and continued for at least 30 seconds after the first breath. In the case of 1 baby, who was delivered breach, the transducer was passed as soon as the face was seen and the mask was applied immediately on delivery.

Catecholamine measurements. Umbilical cord venous and arterial blood samples were taken at 16 unselected emergency CS deliveries. Of these, 7 paired samples were obtained from babies in the lung function study group. The collection, storage, and measurement of plasma catecholamines using liquid chromatography with electrochemical detection has been described. ${ }^{14}$ Where plasma volume was sufficient, duplicate analysis was performed. In view of the skewed distribution of the catecholamine data, $\log _{10}$ transformation was used for statistical analysis.

\section{Results}

Lung function measurements. The results of measurements in this study are compared with those of our previous study ${ }^{6}$ in Table 2. Although 11 studies were carried out, volume data were obtained only in 9 babies because of mechanical problems in achieving a face seal. In 6 of the 9 babies air started to enter the lungs as soon as the intrathoracic pressure fell from the baseline level. In the other 3 babies an opening pressure of $1.2 \mathrm{kPa}\left(12 \mathrm{~cm} \mathrm{H}_{2} \mathrm{O}\right)$ was not exceeded.

\section{Squeeze pressures}

The squeeze pressure-the pressure that is applied 
514 Vyas, Milner, Hopkin, and Falconer

Table 2 Results of pressure and volume studies

\begin{tabular}{|c|c|c|c|c|c|}
\hline $\begin{array}{l}\text { Mode of delivery } \\
\text { No) }\end{array}$ & $\begin{array}{l}\text { Inspiratory pressure } \\
(k P a) \\
(\text { mean } \pm S D)\end{array}$ & $\begin{array}{l}\text { Expiratory pressure } \\
(k P a) \\
(\text { mean } \pm S D)\end{array}$ & $\begin{array}{l}\text { Inspiratory volume } \\
(m l) \\
(\text { mean } \pm S D)\end{array}$ & $\begin{array}{l}\text { Functional residual } \\
\text { capacity }(m l) \\
(\text { mean } \pm S D)\end{array}$ & $\begin{array}{l}\text { Delivery pressure } \\
(k P a) \\
(\text { mean } \pm S D)\end{array}$ \\
\hline $\begin{array}{l}\text { Emergency caesarean } \\
\text { section (11) }\end{array}$ & $5 \cdot 1 \pm 1 \cdot 4$ & $8 \cdot 6 \pm 3 \cdot 5$ & $42 \cdot 0 \pm 13 \cdot 7$ & $20 \cdot 7 \pm 11 \cdot 1$ & $8 \cdot 7 \pm 4 \cdot 5$ \\
\hline $\begin{array}{l}\text { Elective caesarean } \\
\text { section (12) }\end{array}$ & $4 \cdot 0 \pm 2 \cdot 1$ & $5 \cdot 4 \pm 3 \cdot 6$ & $33 \cdot 4 \pm 20 \cdot 7$ & $10 \cdot 8 \pm 16 \cdot 3$ & $7 \cdot 6 \pm 3 \cdot 8$ \\
\hline Vaginal (21) & $3 \cdot 9 \pm 1 \cdot 9$ & $7 \cdot 2 \pm 3 \cdot 1$ & $37 \cdot 2 \pm 18 \cdot 6$ & $18.9 \pm 12.3$ & $15 \cdot 0 \pm 5 \cdot 4$ \\
\hline
\end{tabular}

Conversion: SI to traditional units-inspiratory and expiratory pressures $1 \mathrm{kPa} \approx 10 \mathrm{cmH}_{2} \mathrm{O}$; delivery pressure $1 \mathrm{kPa} \approx 10 \mathrm{cmH}_{2} \mathrm{O}$.

around the baby's thorax during delivery through the uterine incision was mean (SD), $8.7(4 \cdot 5) \mathrm{kPa}$ $\left(1 \mathrm{kPa}=10 \mathrm{~cm} \mathrm{H}_{2} \mathrm{O}\right)$. The corresponding value we obtained in elective CS babies in our previous study was mean (SD), $7.6(3.8) \mathrm{kPa}^{6}$ Although there was no statistically significant difference between the 2 groups, 4 babies in the emergency CS group had a delivery squeeze pressure of over $8 \mathrm{kPa}$ and $2 \mathrm{had}$ values of $10.3 \mathrm{kPa}$ and $20.4 \mathrm{kPa}$ which approach those of babies delivered vaginally. Unlike vaginally delivered babies, however, squeeze pressure was applied for a brief period of usually less than 10 seconds.

\section{Inspiratory pressure}

The highest negative inspiratory pressure recorded on these babies was mean (SD), $5 \cdot 0(1 \cdot 4) \mathrm{kPa}$ and did not differ appreciably from that recorded for babies delivered by elective CS, mean $3.9 \mathrm{kPa}{ }^{6}$ One baby only required negative intrathoracic pressures of greater than $7.0 \mathrm{kPa}$ to expand his lungs.

\section{Expiratory pressure}

Expiratory pressure generated during the first cry was mean (SD), $8.6(3.5) \mathrm{kPa}$, but in 5 babies these pressures exceeded $10 \mathrm{kPa}$. The expiratory pressure generated by our elective CS babies was mean $5.3 \mathrm{kPa}^{6}$ These differences were statistically significant at a level of $2 \%$.

\section{Inspiratory volume and FRC formation}

The inspiratory volume change at the first breath was mean (SD), $42.0(13.7) \mathrm{ml}$ and the range was 27-71.4 ml. The initial FRC was mean (SD), $22.0(11 \cdot 1) \mathrm{ml}$, and range $10 \cdot 4-38.1 \mathrm{ml}$. The mean FRC after emergency CS delivery was not appreciably different from that of babies delivered vaginally. ${ }^{6}$

\section{Opening pressure}

Pressure volume loops were constructed manually using data obtained at $50 \mathrm{~ms}$ intervals. As in the previous study $^{6}$ we did not observe high opening pressures.
Table 3 Results of the catecholamine study

\begin{tabular}{lllll}
\hline $\begin{array}{l}\text { Indications for } \\
\text { caesarean section }\end{array}$ & $\begin{array}{l}\text { No of } \\
\text { deliveries }\end{array}$ & $\begin{array}{l}\text { Duration } \\
\text { of labour } \\
\text { (hours) } \\
\text { (mean, } \\
\text { range) }\end{array}$ & $\begin{array}{l}\text { Range of } \\
\text { umbilical } \\
\text { arterial } \\
\text { noradrenaline } \\
\text { concentration } \\
\text { (nmol/l) }\end{array}$ & $\begin{array}{l}\text { Apgar } \\
\text { score } \\
(2 \mathrm{~min})\end{array}$ \\
\hline Fetal distress & 6 & $\begin{array}{l}8 \cdot 2 \\
(4-13) \\
12 \cdot 25\end{array}$ & $4 \cdot 0-353$ & $8-10$ \\
$\begin{array}{c}\text { Cephalopelvic } \\
\text { disproportion }\end{array}$ & 5 & $2 \cdot 1-4 \cdot 3$ & $5-7$ \\
$\begin{array}{c}\text { Antepartum } \\
\text { haemorrhage }\end{array}$ & 2 & $\begin{array}{l}6-25 \\
(6-6 \cdot 5)\end{array}$ & $1 \cdot 07-7 \cdot 8$ & 8 \\
$\begin{array}{c}\text { Breech } \\
\text { presentation }\end{array}$ & 3 & $\begin{array}{l}6 \cdot 6 \\
(3-12)\end{array}$ & $3 \cdot 8-7 \cdot 5$ & $5-9$ \\
\hline
\end{tabular}

Conversion: SI to traditional units-noradrenaline $1 \mathrm{nmol} / 1 \approx 16 \cdot 9 \mathrm{ng}$ / $100 \mathrm{ml}$.

Catecholamine concentrations. The results of the umbilical noradrenaline concentrations varied widely (Table 3). High values for arterial noradrenaline were associated with fetal distress (diagnosed as a change in the fetal heart rate record) in 4 babies. In 2 babies with fetal distress, however, plasma concentrations of noradrenaline were similar to those recorded in babies delivered by emergency CS for other indications. The lowest plasma arterial noradrenaline value, $1.07 \mathrm{nmol} / 1(18.03 \mathrm{ng} / 100 \mathrm{ml})$, was recorded in the infant delivered to a mother receiving methyl dopa. Low plasma noradrenaline concentrations were found in 6 of the 7 infants in whom lung function was also studied (Figure (a)). Arterial plasma noradrenaline concentrations were higher than the venous values in all infants (Figure (a)).

Umbilical arterial plasma adrenaline concentrations were lower than noradrenaline concentrations in all infants (Figure (b)). In 5 babies they were below the detectable limit for this assay $(0.5 \mathrm{nmol} / 1$ $(9.15 \mathrm{ng} / 100 \mathrm{ml}))$. The arterial plasma adrenaline value was mean (SD), $2.29(1.04) \mathrm{nmol} / 1(41.9 \mathrm{ng} / 100 \mathrm{ml})$. There was no correlation between the length of labour and arterial plasma catecholamine concentrations. 


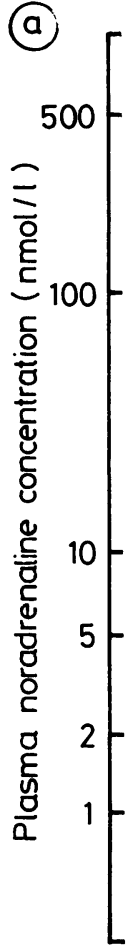

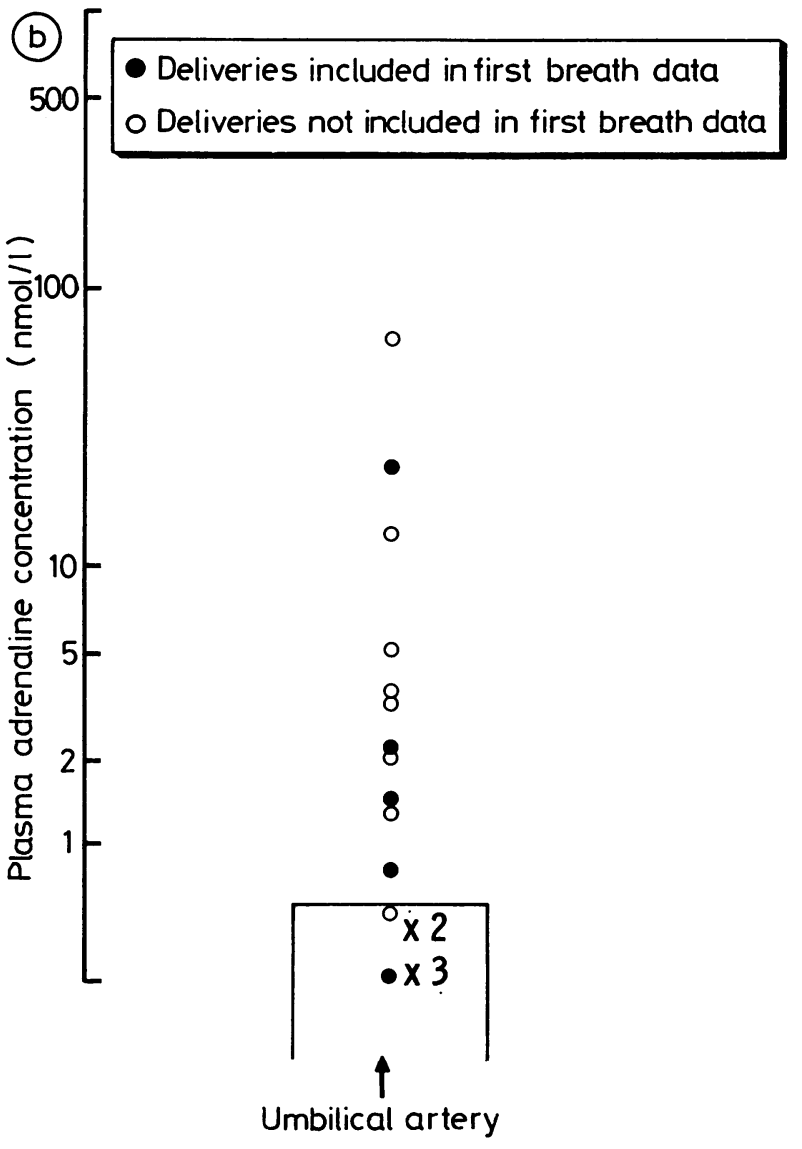

Figure 1(a) Umbilical arterial and venous noradrenaline concentrations from 16 babies delivered by emergency caesarean section.

(b) Umbilical arterial adrenaline concentrations for 16 babies delivered by emergency caesarean section. The 5 values included in the box were below the detectable limit.

\section{Discussion}

The mean inspiratory pressure in this study was higher than that observed previously. ${ }^{6}$ A possible explanation for this is that in some of the babies first breaths may have been gasps. This is borne out by the finding that the highest inspiratory pressure was in the baby in case 9 (Table 1) who had an arterial noradrenaline concentration of $179 \mathrm{nmol} / 1(30.25 \mathrm{ng} /$ $100 \mathrm{ml}$ ) indicating fetal distress. ${ }^{15}$ The expiratory pressures were certainly much higher than we observed in the previous study, ${ }^{6}$ and again we did not observe the high opening pressure phenomenon seen almost universally in isolated lung preparations. ${ }^{16}$ This study confirms our belief that spontaneously breathing babies rarely have to resort to high opening pressures to allow air into their lungs.
The mean inspiratory volume change was similar to values observed previously. ${ }^{6}$ All our babies formed an FRC at the end of their first breath and the amount of air remaining in their lungs was almost identical to that in the vaginally delivered group. ${ }^{6}$ This contrasted with the babies delivered by elective CS in whom 6 of 11 failed to form an FRC.

Delivery pressure, expiratory pressure, and labour may be important factors in the establishment of the FRC, and this study was carried out to ascertain their role in lung expansion at birth. We found that the values for all 3 factors in the babies delivered by emergency CS were different from those found in the elective CS study ${ }^{6}$ perhaps explaining the difference in the formation of an FRC between the 2 groups. 
Delivery pressure. All our mothers were contracting regularly and had ruptured membranes when they underwent CS. Although there is no supporting evidence, it is possible that once the fetal membranes have ruptured, if the seal between the baby's head and the cervix is incomplete at the beginning of a contraction, or the head has entered the birth canal, lung fluid is expelled by direct uterine contraction upon the fetal thorax. Although the differences do not reach statistical significance, the squeeze pressure observed after the delivery of the head was higher among emergency than elective CS babies. ${ }^{6}$ Neither induction agents nor inhalation anaesthetics are thought to affect uterine tone and Crawford ${ }^{17}$ has shown that $0.4 \%$ halothane used normally for CS does not affect the uterus. Thus the babies delivered through a tonic contracting uterus were subjected to much greater thoracic squeeze than babies delivered by elective CS-perhaps increasing the expulsion of lung fluid.

Expiratory pressure. The first inspiration is almost always followed by a strong and prolonged expiratory effort. Bosma et al. ${ }^{18}$ have shown that during this procedure there is pharyngo-laryngeal closure. This mechanism which prevents air escaping from the lungs and resemblesalonggrunt has been shown toaid oxygenation in the hours after birth. The expiratory pressures we found were much higher in the emergency CS than in the elective CS and the vaginally delivered babies.

Labour. In the human neonate noradrenaline is the principal circulating catecholamine. ${ }^{10-12}$ Similar observations have been made in sheep, ${ }^{9}$ however, and Jones et al. ${ }^{19}$ reported raised values for both adrenaline and noradrenaline in sheep. In this study plasma adrenaline concentrations were below those of noradrenaline in all the babies and in 5 babies the plasma adrenaline concentration was below the detectable value.

Evidence suggests that the process of labour stimulates catecholamine release in both the animal and the human fetus. ${ }^{920}$ Lagercrantz et al. ${ }^{20}$ have shown serial increases in fetal scalp plasma noradrenaline and adrenaline concentrations with increasing cervical dilation. These observations may be explained by hypoxia which has been shown to induce catecholamine release from adrenal medulla and extrachromaffin tissue in fetal sheep. ${ }^{21}$ In the human neonate evidence of venous hypoxia after spontaneous vaginal delivery has been associated with raised arterial plasma noradrenaline concentrations. ${ }^{11}$ Further observations ${ }^{11}$ have shown that elective CS delivery representative of an undistressed fetal state was associated with a noradrenaline concentration of mean (SEM), $5 \cdot 2(0 \cdot 71) \mathrm{nmol} / 1$ $(87.88(11.99) \mathrm{ng} / 100 \mathrm{ml})$ compared with a value of mean (SD), $21.88(0.8) \mathrm{nmol} / 1$ (369.7 (13.52) ng/100 $\mathrm{ml}$ ) in the vaginally delivered group. Irestedt et al $^{22}$ reported a noradrenaline concentration of mean (SD), $3.2(2.7) \mathrm{nmol} / \mathrm{l}(54(45.63) \mathrm{ng} / 100 \mathrm{ml})$ for infants delivered by elective CS under general anaesthesia, and mean (SD), $9 \cdot 5(6 \cdot 4) \mathrm{nmol} / 1(160 \cdot 55(108 \cdot 16) \mathrm{ng} /$ $100 \mathrm{ml}$ ) for infants delivered by CS under epidural anaesthesia. The adrenaline concentrations for these 2 groups were mean (SD), $1.0(1.4) \mathrm{nmol} / 1(18.3$ $(25.62) \mathrm{ng} / 100 \mathrm{ml})$ and $4.0(4.5) \mathrm{nmol} / \mathrm{l}(73.2$ $(82 \cdot 35) \mathrm{ng} / 100 \mathrm{ml})$ respectively.

Our study shows a wide range of umbilical plasma noradrenaline concentrations with the highest values associated with the 4 babies delivered by emergency CS for fetal distress. The pattern for plasma adrenaline concentrations was similar, although the absolute values were lower. Brown et al. ${ }^{9}$ have shown a highly sensitive adrenaline mediated reabsorptive mechanism for lung liquid in sheep and it is possible that although the concentrations of adrenaline reported in this study were low they were above the threshold for this mechanism. It is possible that the length of exposure to adrenaline is more important in suppressing lung liquid formation than the absolute concentration and that this explains the differences in the formation of the FRC observed in our elective ${ }^{6}$ and emergency CS studies.

\section{References}

1 Segal C, Chu J. Proceedings of Interdisciplinary Conference on Neonatal Respiratory Adaptation. Publication 1432. US Public Health Service, 1963: 183-8.

2 Brice JEH, Walter CHM.Changing patterns of respiratory distress in the newborn. Lancet 1977; ii: 752-4.

3 Chiswick ML, Milner RDG. Crying vital capacity: measurement of neonatal lung function. Arch Dis Child 1976; 51: 22-7.

4 Milner AD, Saunders RA, Hopkin IE. Effects of delivery by caesarean section on lung mechanics and lung volume in the human neonate. Arch Dis Child 1978; 53: 545-8.

5 Boon AW, Milner AD, Hopkin IE. Lung volumes and lung mechanics in babies born vaginally and by elective and emergency lower segmental caesarean section. J Pediatr 1981; 98: 812-5.

6 Vyas H, Milner AD, Hopkin IE. Intrathoracic pressure and volume changes during the spontaneous onset of respiration in babies born by caesarean section and by vaginal delivery. J Pediatr 1981; 99: 787-91.

7 Bland RD, Bressack MA, McMillan DD. Labor decreases the lung water content of newborn rabbits. Am J Obstet Gynecol 1979; 135: 364-7.

8 Walters DV, Olver RE. The role of catecholamines in lung liquid absorption at birth. Pediatr Res 1978; 12: 239-42.

- Brown MJ, Olver RE, Ramsden CA, Strang LB, Walters DL. Effects of adrenaline infusion and of spontaneous labour on lung liquid secretion and absorption in the fetal lamb (abstract). $J$ Physiol 1980; 313: 13P-4P. 
10 Eliot RJ, Lam R, Leake RD, Hobel CJ, Fisher DA. Plasma catecholamine concentrations in infants at birth and during the first 48 hours of life. $J$ Pediatr 1980; 96: 2: 311-5.

11 Falconer AD, Lake DM. Circumstances influencing umbilical cord plasma catecholamines at delivery. $\mathrm{Br} J$ Obstet Gynaecol 1982; 89:44-9.

12 Lagercrantz H, Bistoletti P. Catecholamine release in the newborn infant at birth. Pediatr Res 1977; 11 : 889-93.

13 Nakai T, Yamada R. The secretion of catecholamines in newborn babies with special reference to fetal distress. J Perinat Med 1978; 6: 39-45.

14 Falconer AD, Powles AB. Plasma noradrenaline levels during labour: influence of elective lumbar epidural blockade. Anaesthesia 1982; 37: 416-20.

15 Datta S, Ostheimer GW, Weiss JB, Brown WU, Jr, Alper MH. Neonatal effect of prolonged anesthetic induction for caesarean section. Obstet Gynaecol 1981; 58: $331-5$.

16 Gruenwald P. Normal and abnormal expansion of the lungs of newborn infants obtained at autopsy. II. Opening pressure, maximal volume, and stability of expansion. Lab Invest 1963; 12: 563-76.

17 Crawford JS. Principles and practice of obstetric anaesthesia, fourth edition. Oxford: Blackwell, 1978: 256.

18 Bosma JF, Lind J, Gentz N. Motion of the pharynx association with initial aeration of the lungs of the newborn infant. Acta Paediatr Scand [Suppl] 1959; Supplement 48, 117-22.

19 Jones CT, Robinson RO. Plasma catecholamines in fetal and adult sheep. J Physiol 1975; 248 : 15-33.

20 Lagercrantz H, Bistoletti P, Nylund L. Sympathoadrenal activity in the fetus. In: Stern L, ed. Intensive care in the newborn. Vol. III. Paris: Masson, 1981 : 1-12.

21 Comline RS, Silver M. The release of adrenaline and noradrenaline from the adrenal glands of the foetal sheep. $J$ Physiol 1961 ; 156: 424-44.

22 Irestedt L, Lagercrantz $H$, Hjemdal $P$, Hägneisk $K$, Belfrage P. Fetal and maternal plasma catecholamine levels at elective cesarean section under general epidural anesthesia versus vaginal delivery. Am J Obst Gynecol 1982; 142: 1004-10.

Correspondence to Professor A D Milner, Department of Neonatal Medicine and Surgery, City Hospital, Hucknall Road, Nottingham NG5 1PB.

Received 3 March 1983

\section{Notice to contributors}

Please note that revised guidelines for the submission of manuscripts have been printed inside the front cover of this journal and, in particular, that two copies of papers should be submitted. 